\title{
A new method of auditing surgical mortality rates: application to a group of elderly general surgical patients
}

\author{
DAVID GWYN SEYMOUR，ROBERT PRINGLE
}

\begin{abstract}
In a prospective study of 505 patients aged 65 years or over admitted to a general surgical unit the overall hospital mortality rate was $14.5 \%$ and the postoperative mortality rate $12.0 \%$. These rates fell to $3.6 \%$ and $5.8 \%$ respectively when deaths in non-viable patients were excluded from the analysis. An audit of surgical outcome that fails to identify non-viable patients is therefore potentially misleading. A standardised system of reporting surgical mortality is proposed to aid the comparison of results from different units. The key elements of this system are (a) the separation of the results from nonviable and potentially viable patients; $(b)$ the consideration of both operative and non-operative mortality; (c) the differentiation between medical and surgical causes of postoperative mortality; and (d) the identification of patients who are discharged from the unit but who have residual malignancy. Data presented in such a way should be of direct relevance to surgeons and physicians who are seeking ways of improving the service provided for surgical patients of all ages.
\end{abstract}

\section{Introduction}

In recent years many British surgeons have introduced systems of audit to their wards. ${ }^{1-13}$ Early reports of their experience and

Royal Victoria Hospital, Dundee DD2 1SP

DAVID GWYN SEYMOUR, BSC, MRCP, senior registrar in geriatric medicine

Ninewells Hospital and Medical School, Dundee DD1 9SY ROBERT PRINGLE, CHM, FRCS, consultant surgeon that of others have emphasised the educational benefits 4581112 and, to a lesser extent, the improvements in the care of patients 814 that internal audit can bring.

When audit is used to compare the outcome of surgical treatment in more than one centre, however, several problems emerge. ${ }^{+1516} \mathrm{~A}$ major difficulty is the lack of a standardised method of measuring surgical outcome suitable for use in centres that differ in such respects as the average age and fitness of patients referred, and the range and urgency of surgery performed. ${ }^{1+16}$ Because of this problem of definition, the tendency has been to fall back on the relatively crude measurement of outcome provided by mortality rates. ${ }^{46} 15$

The present study has evaluated the use of mortality rates as a method of measuring outcome in a group of elderly surgical patients. The results have indicated that the overall mortality rate is a grossly inadequate means of assessing surgical performance. In view of these findings we offer a new method of classifying deaths in surgical patients which provides a more sensitive means of comparing results from different units and centres.

\section{Patients and methods}

A prospective study was made of 505 patients aged 65 years and over who were admitted to a general surgical unit in Ninewells Teaching Hospital, Dundee. Day cases were excluded. The final sample contained 261 men and 244 women aged between 65 and 96 . Patients were observed until their discharge from the surgical unit or until their death in hospital.

\section{SURGICAL PROCEDURES}

Surgical procedures were classified as either operations or minor procedures. Operations included all laparotomies and thoracotomies, mastectomies, operations on thyroid and parathyroid glands, hernia repair, varicose vein stripping and ligation, and excision of haemor- 
rhoids. Minor procedures comprised flexible and rigid endoscopy (with or withuut biopsy, excision, or bouginage), removal of cutaneous or small subcutaneous lesions, and arteriography.

\section{CLASSIFICATION OF DEATHS}

Patients who died were classified at the time of death as follows:

\section{A Non-viable}

Here it was judged that death could not have been prevented by surgical intervention, or a modification of surgical procedure, or an alteration in preoperative, intraoperative, or postoperative care.

This group was subdivided into those with:

(1) Advanced malignancy with surgery performed for diagnostic or palliative reasons.

(2) Advanced malignancy, with no surgery performed.

(3) No malignancy, but underlying disease not amenable to surgical intervention-for example, myocardial infarction presenting as abdominal pain, massive bowel infarction, or stroke complicating a surgical illness.

\section{B Potentially viable}

The potentially viable group were patients dying in the surgical unit who did not fall into the non-viable category. This group was subdivided into:

(1) Postoperative deaths due to a surgical complication.

(2) Postoperative deaths due to a medical complication.

(3) Non-operative deaths, where surgery offered a chance of cure, however small-for instance, ruptured aneurysm or peritonitis in a moribund patient.

\section{Results}

NATURE OF SURGERY

The 258 general surgical operations performed on patients aged 65 and over consisted of 13 thoracotomies, 34 biliary procedures, 115 other abdominal procedures, 56 herniorrhaphies, and 40 miscellaneous procedures. Thirty-four of these operations were in patients with inoperable malignancy: 16 were of an "open and close" nature, while 18 entailed some type of palliative procedure.

\section{DEATHS IN NON-VIABLE AND POTENTIALLY VIABLE PATIENTS}

Of the 505 elderly patients who were admitted, 73 died in hospital -an overall mortality rate of $14.5^{\circ}$. Thirty-one of these deaths followed surgery and six occurred in patients admitted for minor procedures. A further 36 deaths occurred in patients who had neither surgery nor a minor procedure (figure).

The figure also separates the deaths into "non-viable" and "potentially viable" categories, as previously defined. This corrects a number of false impressions that might have been created by the use

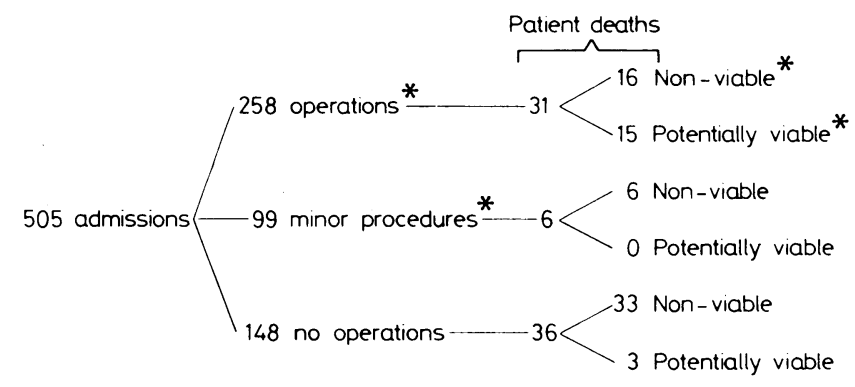

* As defined in the patients and methods section

Summary of deaths in 505 patients aged 65 years and over admitted to a general surgical unit. of the overall death rate alone. This is best illustrated by table I where deaths in non-viable patients are excluded. It may be seen from this table that, in patients undergoing surgery, exclusion of the non-viable group reduced the postoperative mortality rate by half, from $12.0 \%$ to $5 \cdot 8^{\circ} \%$. All deaths after minor procedures were due to the underlying disease rather than the procedure itself, and the mortality rate after excluding non-viable cases was therefore zero. Only three of the 36 non-operative deaths were in potentially viable patients. Thus the overall mortality rate fell from $14 \cdot 5^{\circ}{ }^{\prime}$ to only $3.6 \%$ when all non-viable cases were excluded.

TABLE I-Mortality rates including and excluding nonviable cases

\begin{tabular}{|c|c|c|}
\hline Patient group & $\begin{array}{l}\text { Overall } \\
\text { mortality } \\
\text { rate }\end{array}$ & $\begin{array}{c}\text { Mortality } \\
\text { rate when } \\
\text { non-viable } \\
\text { patients } \\
\text { excluded }\end{array}$ \\
\hline $\begin{array}{l}\text { Postoperative }(n=258) \\
\text { Minor procedures }(n=99) \\
\text { No operation }(n=148)\end{array}$ & $\begin{array}{l}12 \cdot 0^{\prime \prime \prime} \\
6 \cdot 1 "{ }^{\prime \prime \prime} \\
24 \cdot 3^{\prime \prime " ~}\end{array}$ & $\begin{aligned} 5 \cdot 8 " \prime \prime \\
0 " ", \\
2 \cdot 0 " 1,\end{aligned}$ \\
\hline All patients & $14.5 \%$ & $3 \cdot 6 " 0$ \\
\hline
\end{tabular}

Of the 432 patients who were discharged from the unit, 35 had evidence of residual malignancy. Three of these patients had advanced malignancies and were transferred to a hospice for terminal care. Of the remainder, five had been found to be totally inoperable at the time of surgery, 13 had undergone palliative procedures only, and 14 had been judged inoperable by non-surgical methods of investigation.

CAUSES OF DEATH

Table II gives a breakdown of the causes of death, with patients divided into viable and non-viable categories.

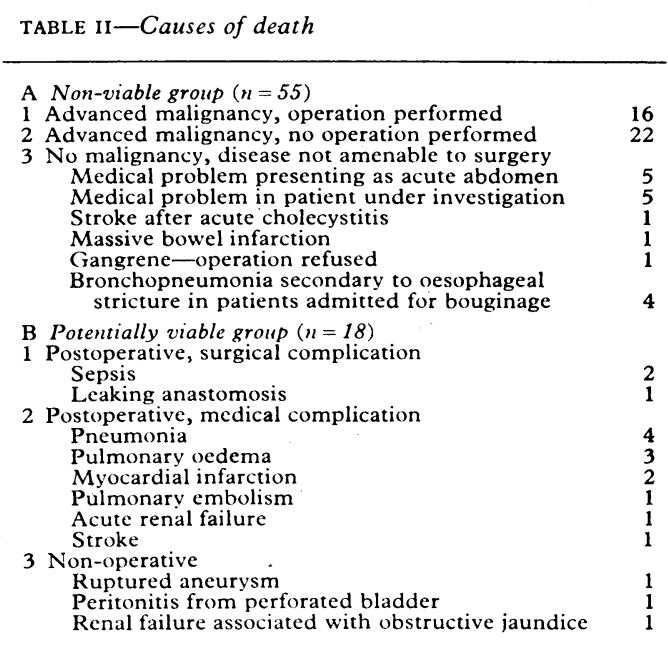

\section{A Non-viable patients}

Of the 16 patients in group A1, five had palliative surgery while 11 had a laparotomy of the "open and close" type. In total, 38 of the 55 deaths in the non-viable group were attributable to malignancy.

The single patient who refused potentially life-saving surgery was classified in the non-viable category A3.

\section{B Potentially viable patients}

Interestingly, in the potentially viable group only three of the postoperative deaths were "surgical" in nature (group B1), with the remaining 12 postoperative deaths (group B2) being attributed to 
"medical" causes. The three potentially viable patients who did not receive surgery (group B3) were all referred late in the course of their surgical disease, and the scope for operative intervention was therefore small.

\section{EFFECT OF AGE AND EMERGENCY ADMISSION ON MORTALITY}

Tables III and IV show how age and urgency of surgery, respectively, affected the ratio of deaths in the non-viable and potentially viable categories. In the potentially viable group the mortality rate in the over 75 s was four to five times that of the 65 to 74 age group. A similar degree of excess mortality was seen when emergency patients were compared with elective patients.

TABLE III-Age and mortality rates

\begin{tabular}{lcc}
\hline \multicolumn{1}{c}{ Age group } & $\begin{array}{c}\text { Overall } \\
\text { mortality } \\
\text { rate }\end{array}$ & $\begin{array}{c}\text { Mortality } \\
\text { rate when } \\
\text { non-viable } \\
\text { patients } \\
\text { excluded }\end{array}$ \\
\hline 65 to $74(n=294)$ & $\begin{array}{c}9.9 \% \\
\text { Over } 75(n=211)\end{array}$ & $\begin{array}{c}1.4 \% \\
6.6 \%\end{array}$ \\
\hline All patients $(n=505)$ & $14.5 \%$ & $3.6 \%$ \\
\hline$* 2 \times 2 \chi^{2}=10.0, p<0.005$. & & \\
\hline
\end{tabular}

TABLE IV-Urgency of admission and mortality rates

\begin{tabular}{lcc}
\hline Type of admission & $\begin{array}{c}\text { Overall } \\
\text { mortality } \\
\text { rate }\end{array}$ & $\begin{array}{c}\text { Mortality } \\
\text { rate when } \\
\text { non-viable } \\
\text { patients } \\
\text { excluded }\end{array}$ \\
\hline Elective $(n=297)$ & $\begin{array}{r}6.7 \% \\
\text { Emergency }(n=208)\end{array}$ & $\begin{array}{c}1.3 \% * \\
6.7 \% *\end{array}$ \\
\hline All patients $(n=505)$ & $14.5 \%$ & $3.6 \%$ \\
\hline$* 2 \times 2 \chi^{2}=10.4, p<0.005$. & & \\
\hline
\end{tabular}

\section{Discussion}

Our study has shown that non-viable patients accounted for half the postoperative mortality and three-quarters of the overall mortality of a group of elderly people admitted to a general surgical ward. Deaths in such patients could not have been avoided by any means available at the stage of the illness which presented to the surgeon. Thus the common practice of judging surgical success in terms of the overall mortality rate (which groups together deaths in both non-viable and potentially viable patients) is both unsatisfactory and misleading. Our data have also indicated that the non-viable and potentially viable groups are themselves heterogeneous and that further subdivision is desirable when audit is undertaken.

\section{COMPARISON WITH OTHER STUDIES}

Most of the earlier studies of mortality rates in elderly general surgical patients fail to distinguish between deaths in non-viable and potentially viable patients and consider postoperative mortality only. ${ }^{17-21}$ It is therefore difficult to compare their findings with our own. In more recent studies, ${ }^{311} 1222{ }^{23}$ which give the non-operative mortality rate, direct comparison is still difficult as non-viable cases are not clearly defined. This problem of definition even applies to the study of Griffiths, ${ }^{22}$ who appears to have been the first author to use the term "nonviable" in the context of surgical audit.

The danger of ignoring the contribution of non-viable cases to postoperative mortality may be shown by comparing our own findings with those reported by Gilmore et ${ }^{1 l^{11}}$ in Hackney. Our own postoperative mortality rate, when non-viable patients were excluded, was $5 \cdot 8 \%$, which appears to be practically identical with that found after major surgery in Hackney, even though the patients there were, on average, younger than ours. If nonviable cases are included, however, our overall postoperative mortality rate appears much worse than that found in Hackney $(12.0 \%$ as compared with under $7 \%$ ), simply because more of the patients admitted to the Dundee unit were beyond the help of curative surgery at the time of referral.

The value of distinguishing between medical and surgical causes of postoperative deaths in potentially viable patients can also be inferred from previous work. Data from four studies ${ }^{312} 22$ support our own finding that medical causes of postoperative deaths outnumber surgical causes in middle-aged and elderly people. Thus even if the surgical type of complication was completely abolished in these studies fewer than half of the postoperative deaths of potentially viable patients would be avoided.

\section{FACTORS INFLUENCING THE NUMBER OF DEATHS IN THE} NON-VIABLE CATEGORY

Artefacts-Retrospective reviews of case notes are likely to misclassify deaths and for this reason prospective studies are preferable: Artefacts will also tend to arise if large numbers of patients are discharged elsewhere for terminal care, ${ }^{12}$ thus reducing the postoperative hospital mortality rate of non-viable patients. This error can be avoided if patients leaving hospital with residual malignancy are clearly identified, as we propose.

Nature of surgery-The range and type of surgery performed on a unit will tend to affect the number of deaths that are assigned to non-viable or potentially viable categories. Surgeons operating on the abdomen are likely to encounter relatively large numbers of carcinomas, ${ }^{18}$ some of which will be inoperable, whereas in orthopaedic, accident, or vascular units, deaths due to malignancy will tend to be less common. ${ }^{23}$

Age-While the present study deals only with patients over 65 , there is no reason why the proposed scheme of audit should not be applied to younger patients. Data from previous studies, 112 however, suggest that the proportion of deaths falling into the non-viable category will be smaller in younger surgical subjects.

Non-operative deaths-A low postoperative death rate in elderly people admitted to a surgical unit may be achieved by excluding from surgery all but the very fittest subjects. ${ }^{123}$ Such a policy, however, will tend to increase the number of nonoperative deaths that are allocated to the potentially viable category. Thus our proposed system of audit, which considers both operative and non-operative deaths in potentially viable patients, should make it possible to detect whether preoperative exclusion criteria are being applied unusually strictly.

Referral delays-It seems reasonable to assume that delays in diagnosing or referring patients with carcinoma will tend to increase the proportion of patients who are found to be beyond surgical cure at the time of admission or at operation. If such patients die in hospital they will be placed in the non-viable category. Even if they survive to leave hospital they will still be identifiable as "patients with residual malignancy." Thus if a unit has a relatively high proportion of patients in either of these two categories this might indicate that excessive delays in diagnosis or referral are occurring. At present this line of argument is speculative, but if it is borne out by clinical experience it would be a major reason for adopting this proposed new system of audit.

\section{Conclusions and recommendations}

We recommend that when mortality rates are used to audit surgical outcome in adults of all ages the following data should be collected:

(1) Detailed background data including age range of patients, 
type of surgery performed, and the ratio of elective to emergency cases.

(2) The total number of deaths occurring on the unit, both in non-operated and operated patients, together with the number of patients leaving hospital with residual malignancy.

(3) A clear separation of patient deaths in hospital into nonviable and potentially viable categories, as defined above. The non-viable group should be further subdivided into: operated cases with malignancies, non-operated cases with malignancies, and cases without malignancies. The potentially viable group should be subdivided into: postoperative deaths from a surgical complication, postoperative deaths from a medical complication, and non-operative deaths.

\section{References}

${ }^{1}$ McColl I. Observations on the quality of surgical care. In: McLachlan G, ed. A question of quality? Oxford: Oxford University Press, 1976.

2 Irving $M$, Temple J. Surgical audit: one year's experience in a teaching hospital. Br Med f 1976;ii :746-7.

${ }^{3}$ Salem R, Devitt P, Johnson J, Firmin R. Emergency geriatric surgical admissions. Br Med F 1978; ii :416-7.

${ }^{4}$ McColl I. Medical audit in British hospital practice. Brf Hosp Med 1979; $22: 485-90$.

${ }^{5}$ Fielding LP, Stewart-Brown S, Blesovsky L. Large-bowel obstruction caused by cancer: a prospective study. $B r$ Med f 1979;ii :515-7.

6 Shaw CD. Aspects of audit. The background. $\mathrm{Br}$ Med F 1980;280:1256-8.

7 Shaw CD. Aspects of audit. Audit in British hospitals. Br Med $\mathcal{F}$ 1980; 280:1314-6.
${ }^{8}$ Shaw CD. Aspects of audit. Acceptability of audit. $\mathrm{Br}$ Med $\mathcal{F} 1980 ; 280$ : 1443-6.

9 Shaw CD. Aspects of audit. Looking forward to audit. Br Med $\mathcal{F} 1980$; 280:1509-11.

10 Matheson NA, Valerio D. Large-bowel surgery, 1979, self-assessment. Br Med f 1980;281:719-21.

11 Gilmore OJA, Griffiths NJ, Connolly JC, et al. Surgical audit: comparison of the work load and results of two hospitals in the same district. $\mathrm{Br}$ Med $\mathcal{f} 1980 ; \mathbf{2 8 1}: 1050-2$.

12 Gough MH, Kettlewell MGW, Marks CG, Holmes SJK, Holderness J. Audit: an annual assessment of the work and performance of a surgical firm in a regional teaching hospital. $\mathrm{Br} M e d \mathcal{F} 1980 ; 281: 913-8$.

13 Anonymous. Audit: aiming high. $\mathrm{Br} M e d \mathcal{f} 1981 ; \mathbf{2 8 2}: 422$.

14 Collopy BT. A surgical outcome audit. Med F Aust 1979;2:689-91.

15 Goldacre MJ, Harris RI. Mortality, morbidity, resource allocation, and planning: a consideration of disease classification. $B r$ Med $\mathcal{7} 1980 ; 281$ : 1515-9.

${ }^{16}$ Ward A. Surgical audit. Br Med $\mathcal{F} 1981 ; 282: 68$.

17 Palmberg S, Hirsjarvi E. Mortality in geriatric surgery. Gerontology 1979; 25:103-12.

18 Blake R, Lynn J. Emergency abdominal surgery in the aged. Br $\mathcal{F}$ Surg $1976 ; 63: 956-60$.

19 Cogbill CL. Operation in the aged. Arch Surg 1967;94:202-5.

${ }^{20}$ Bonus RL, Dorsey JM. Major surgery in the aged patient. Arch Surg 1965;90:95-6.

${ }^{21}$ Klug TJ, McPherson RC. Postoperative complications in the elderly surgical patient. Am $\mathcal{F}$ Surg 1959;97:713-7.

22 Griffiths JMT. Surgical policy in the over-seventies. Geront Clin 1972;14: 282-96.

23 Andersen B, Genster H, Langberg K. Geriatric surgery in a community. Acta Chir Scand 1965;354,suppl:1-103.

(Accepted 30 March 1982)

\title{
Financial burden of childhood cancer
}

\author{
C M BODKIN, T J PIGOTT, J R MANN
}

Fifty-nine of 73 families of children referred for treatment of cancer during 1980 co-operated in a study of the financial consequences of the illness. Except for two social class I families who declined to take part, the sample was representative of the childhood cancer population and families were of similar socioeconomic status to the general population. During the first, inpatient, week of treatment the sum of income lost plus additional expenditure exceeded $50 \%$ of total income in over $45 \%$ of families. During a subsequent week of outpatient treatment, loss of income plus additional expenditure amounted to more than $20 \%$ of income in over half the families.

These problems affected all the groups studied and were not confined to the lower paid or those living furthest from the centre. Financial help was available from charitable sources and the DHSS towards travel, extra nourishment, and heating costs but could not be obtained

Children's Hospital, Ladywood, Birmingham B16 8ET C M BODKIN, CQSE, Malcolm Sargent Fund social worker T J PIGOTT, medical student

J R MANN, FRCP, consultant paediatric oncologist to compensate for loss of earnings. The families of children who died had difficulty in meeting the cost of funerals. Families of children with cancer need more help than is at present available, especially to offset loss of income and the cost of funerals.

\section{Introduction}

The care of children with cancer creates financial problems and hardship for their families. In an American study ${ }^{1}$ the nonmedical costs of childhood cancer plus loss of parents' pay amounted for half the families surveyed to more than $25 \%$ of their weekly income. To assess the magnitude of the problem in Britain, we studied the families of children referred during 1980 to the regional oncology centre at Birmingham Children's Hospital.

\section{Patients and methods}

A total of 98 newly diagnosed patients were referred during 1980, and on an unselected basis the families of 73 were invited to participate in the study (insufficient time was available to conduct detailed interviews with them all).

A form was designed to record family size and structure, employ- 